\title{
História, imagens e gaúchos: usos, desusos e possibilidades em sala de aula
}

\author{
History, images and gauchos: their uses, \\ misuses and possibilities in the classroom
}

Eliana Ávila Silveira*

Luciana da Costa de Oliveira ${ }^{\star *}$

\section{RESUMo}

O uso de imagens em práticas educativas de sala de aula e nos espaços públicos formativos da memória social e cultural em seus diversificados suportes torna-se cada vez mais frequente. $\mathrm{O}$ emprego renovado e crítico das imagens na educação histórica revela o desenvolvimento de novas linguagens e métodos de ensino. Este artigo objetiva apresentar as múltiplas possibilidades oferecidas pelas imagens como fonte de estudo e compreensão dos lugares da memória social, cultural e artística, além de oferecer estratégias críticas de educação histórica e patrimonial. Para tanto, analisa-se a forma de utilização do gaúcho como elemento problematizador no processo de ensino-aprendizagem, deslocando-a de seu habitual uso como ilustração e percebendo sua contribuição para renovar e estimular o uso de novas metodologias no ensino de história.

Palavras-chave: imagens; educação; arte; gaúcho.

\section{Abstract}

The use of images in educational practices in the classroom and in the public spaces that conform social and cultural memory in their diversified supports becomes more and more frequent. The renewed and critical use of images in historical education reveals the development of new teaching methods. This article aims to present the multiple possibilities offered by the images as a source of study and understanding of the social, cultural and artistic memory places, as well as offering critical historical and patrimonial education strategies. In order to do so, the way of using the gaucho as a problematizing element in the teaching-learning process is analyzed, shifting it from its habitual use as illustration and perceiving its contribution to renew and stimulate the use of new methodologies in history teaching. Keywords: images; education; art; the Gaucho.

\footnotetext{
* Doutora em História, Pontifícia Universidade Católica do Rio Grande do Sul (PUCRS). Porto Alegre, RS, Brasil. silveira.elianaavila@gmail.com

** Doutoranda em História, Pontifícia Universidade Católica do Rio Grande do Sul (PUCRS). Porto Alegre, RS, Brasil. luciana_de_oliveira@hotmail.com
} 


\section{HistóRIAS}

No âmbito das novas abordagens historiográficas e das metodologias aplicadas ao ensino, notadamente aquelas voltadas ao uso de diferentes modalidades de fontes ao lado da documentação escrita e oral, como assinala Peter Burke, há que se considerar o papel relevante assumido pela imagem nos estudos históricos. Com efeito, as imagens podem ser tomadas como ponto de partida tanto para as pesquisas elaboradas pelos historiadores quanto para o trabalho pedagógico desencadeado nas práticas do ensino de história. A necessidade constante de aprimorar as estratégias críticas de leitura das imagens em seus diferentes contextos espaciais e temporais constitui, sem dúvida, elemento essencial para a compreensão das especificidades e complexidades do conhecimento histórico.

Nesse sentido, importa destacar e levantar algumas questões primordiais acerca do uso das imagens. É importante lembrar que o trabalho com a produção imagética pressupõe igualmente o exercício crucial dos procedimentos ligados substancialmente à crítica documental. Não é possível tratar das relações entre imagem e história sem uma reflexão mais aguçada sobre a crítica das fontes. Conforme observa Peter Burke, é de especial relevância destacar os modos de tratamento e exploração das imagens no tecido histórico. Segundo o autor,

Para utilizar a evidência de imagens de forma segura, e de modo eficaz, é necessário, como no caso de outros tipos de fontes, estar consciente das suas fragilidades. A crítica da fonte de documentos escritos há muito tempo tornou-se parte essencial da qualificação dos historiadores. Em comparação, a crítica de evidência visual permanece pouco desenvolvida, embora o testemunho de imagens, como o dos textos, suscite problemas de contexto, função, retórica, recordação. (Burke, 2004, p.26)

Sob o ângulo das práticas docentes voltadas ao ensino de história, notadamente na educação escolar, o trabalho com imagens oferece possibilidades pedagógicas importantes para o desenvolvimento da aprendizagem e da compreensão histórica. A ampliação da compreensão leitora no plano da linguagem visual e o enriquecimento cognitivo na incorporação das noções de espaço, tempo e cenário das ações humanas, ainda que sob o enfoque da 
projeção imagética, associados ao desenvolvimento da sensibilidade estética, sem dúvida constituem elementos importantes no processo de ensino-aprendizagem. Na perspectiva de Maria Belintane Fermiano e Adriana S. dos Santos, podemos sublinhar também estes aspectos do potencial educativo do trabalho com imagens:

É importante que desde cedo as crianças tomem contato com imagens no espaço escolar e aprendam que existem distintas maneiras de observá-las e compreendê-las: a partir de conceitos da lógica intuitiva e imaginativa. A interpretação da pintura de um artista, por exemplo, supõe uma interação dinâmica entre o criador e o espectador. (Fermiano; Santos, 2014, p.184)

Em seu estudo sobre a produção do livro didático e de seus diversos materiais pedagógicos constituídos de textos e imagens, Circe Bittencourt apresenta esta consideração:

Gravuras, fotos, filmes, mapas e ilustrações diversas têm sido utilizados há algum tempo, como recurso pedagógico no ensino de História. Os livros didáticos de História, já em meados do século XIX, possuíam litogravuras de cenas históricas intercaladas aos textos escritos, além de mapas históricos. (Bittencourt, 2009, p.69)

Afora a grande difusão e utilização do livro didático de história, amplamente ilustrado com imagens, especialmente para emprego em atividades de sala de aula, outros suportes da memória social e da produção artística e cultural, configurados no ensino, com efeito, são também marcados por cenas históricas e personagens pautados na construção e apropriação da imagem para explicar o passado histórico. Exposições guiadas, monumentos e painéis da arte pública podem expressar comumente os domínios do imaginário e os construtos da história política e social de uma dada sociedade.

A história do Rio Grande do Sul encontra-se, assim, marcada continuamente pela presença de imagens que visam elucidar ou ilustrar cenas e personagens da sua vida política e social, ao longo do tempo. Contudo, a compreensão dessas construções imagéticas e sua finalidade social ou política nem sempre estão associadas e comportam elementos importantes de análise crítica ou reflexão pedagógica. Para discutir tal problemática, é necessário levantar alguns questionamentos básicos no desenvolvimento das práticas docentes. Convém 
perguntar, portanto: Como promover o entendimento e a compreensão crítica da imagem no contexto das práticas escolares e das metodologias do ensino de História? Como desenvolver projetos que aproximam ensino e pesquisa na educação básica?

Visando justamente perceber esses entornos e entrecruzamentos de saberes é que se propõe delimitar alguns aspectos fundamentais para o desenvolvimento do presente estudo. Fruto de experiências que tiveram seu início em práticas de sala de aula e, posteriormente, foram dirigidas para outros espaços da memória social, as considerações aqui traçadas visam, sobretudo, evidenciar a forma na qual o estudo e a análise de imagens podem estabelecer um rico e profícuo diálogo com a diversidade de abordagens que estão inseridas na perspectiva do conhecimento interdisciplinar. Nesse sentido, ao tramar elementos da história junto àqueles das artes visuais, da história da arte e da educação patrimonial, novos olhares e problematizações podem ser apreendidos. Como forma de trazer à tona tais questões, apresentaremos um projeto problematizado a partir da visitação ao Palácio Piratini, sede do governo do estado do Rio Grande do Sul, onde se encontram grandes murais pictóricos elaborados pelo artista ítalo-brasileiro Aldo Locatelli (1915-1962).

Partindo de premissas pedagógicas segundo as quais o espaço denominado sala de aula deve comportar leituras e dimensões amplas e abertas ao mundo, incorporando inúmeros locais de aprendizagem, tal projeto incluiu diversas atividades de saída a campo. $\mathrm{Na}$ etapa inicial do trabalho, o primeiro contato dos estudantes com as imagens de Locatelli ocorreu no ambiente escolar, mediante o trabalho com fontes iconográficas acompanhadas do estudo de textos históricos, mas foi, contudo, no interior do próprio palácio do governo, durante as visitações, ${ }^{1}$ que grande parte das principais inquietações dos jovens afloraram com especial significação para o processo de aprendizagem. E isso por dois motivos primordiais. O primeiro deles está relacionado, pois, com a experimentação e apropriação do espaço público como espaço de vivência e memória. E o segundo, mais focado na relação entre imagem e história, foi o de colocar o aluno frente à plasticidade da obra de arte. $\mathrm{O}$ fato de serem observadas in loco, integradas, ainda, ao espaço arquitetônico - e político - do prédio, tornou possível o estabelecimento de outro tipo de relação entre os alunos, tornados observadores, e os murais, tornados objetos de estudo. 
Entre as muitas questões levantadas, uma pareceu ser a mais frequente entre os estudantes: a presença do tipo social do gaúcho em um mural de grandes proporções que lá se encontrava. A dúvida entre os estudantes, que surgiu precisamente no encontro deles junto ao gaúcho da pintura de Aldo Locatelli, deveu-se à presença desse tipo sulino na produção artística do Rio Grande do Sul. Mesmo que, de forma mais tímida, ele tenha já se configurado desde o início do século XX na obra de artistas regionais, a maneira pela qual sua imagem foi disseminada - e muitas vezes banalizada - gerou problemas. E um dos mais significativos refere-se, sem dúvida, aos usos que se fizeram das imagens dos gauchos platinos. Assim, teve início igualmente uma pequena história sobre os usos e desusos da imagem.

Outras experiências dos estudantes da escola básica, com imagens pictóricas representando cenas históricas, com efeito, podem ser também vislumbradas em exposições e mostras comemorativas de grandes eventos históricos. Em setembro de 2016, junto às comemorações da Semana Farroupilha, uma exposição histórica que abordava o cotidiano do conflito foi inaugurada em Porto Alegre. O público que foi visitá-la, formado por interessados no tema e, também, por alunos de escolas da capital, pôde observar os mais diversificados objetos e instrumentos que marcaram o dia a dia do conflito. No entanto, entre armamentos antigos, vidros de tinturas variadas e ferros de passar roupa com brasa, foi a reprodução de uma pintura, no centro da sala de exposições, um dos elementos que mais chamaram a atenção.

A obra pictórica em questão trazia, em seu centro, a imagem de um soldado negro que, em uma das mãos, carregava uma lança. Além disso, envolto em uma paisagem crepuscular, lançava seu olhar para o horizonte de forma a não dialogar com o observador. Como problematizar essa imagem? Sua presença na sala trazia várias indagações: quem seria aquele homem? Qual sua função na exposição? Dado o contexto e o espaço em que foi inserido, provavelmente ele estaria ali fazendo alusão aos Lanceiros Negros, agrupamento que lutou na Guerra dos Farrapos e que, posteriormente, foi subjugado.

No entanto, se uma análise a respeito dessa imagem for realizada, ou, ainda, se estudos acerca da construção imagética dos Lanceiros Negros for empreendida, perceberemos que a obra em questão não se refere aos soldados sul-rio-grandenses, tampouco aos Lanceiros Negros. A pintura, elaborada pelo uruguaio Juan Manuel Blanes entre 1860 e 1870, foi intitulada Lancero de la 
época de Rivera e, a não ser pela presença do negro e da lança, em nada se assemelha ao grupo de soldados do Rio Grande do Sul. Assim, em função da proximidade visual que se estabeleceu entre o lanceiro elaborado por Blanes e os lanceiros sulinos que lutaram no conflito, a apropriação da imagem por seu viés ilustrativo acabou por eclipsar sua significação e sentido.

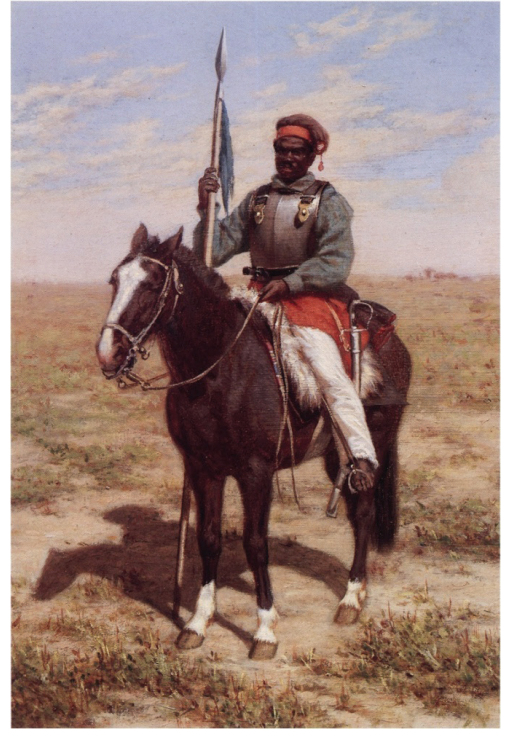

Figura 1 - Juan Manuel Blanes, Lancero de la época de Rivera, óleo sobre tela, $34 \times 24,5 \mathrm{~cm}$, s.d. - Coleção Horácio Porcel, Buenos Aires

Essa mesma pintura, vale dizer, não foi utilizada unicamente na exposição histórica citada. Com grande circulação no Rio Grande do Sul, a imagem ocupou a capa de muitas publicações e ilustra, ainda hoje, diversos sites de internet que tratam da Revolução Farroupilha e dos Lanceiros Negros. Nesse âmbito de análise, outras imagens associadas fortemente à história do Rio Grande do Sul e ao seu processo de construção da identidade regional são aspectos importantes de produção imagética. Em decorrência disso, a inquietação e os questionamentos causados pelo uso da imagem do gaúcho como símbolo identitário regional pôde, sem dúvida, suscitar estratégias relevantes para se problematizar o uso de tais suportes como fonte e documento em sala de aula.

Com o objetivo de salientar as especificidades no entorno das imagens e, também, suas potencialidades como objeto de ensino, buscou-se selecionar para o presente estudo as pinturas elaboradas no palácio do governo pelo 
artista ítalo-brasileiro Aldo Locatelli, especialmente a intitulada A formação histórico-etnográfica do povo rio-grandense. O Palácio Piratini revela, principalmente em sua edificação histórica e nos notáveis murais do artista, que compõem seus importantes espaços internos e salas ricamente ornadas, um conjunto de pinturas extremamente importantes para a percepção da produção artística local, além de contribuir para a compreensão das relações de poder e promover o desenvolvimento de práticas socioeducativas integradas, marcadas pelo sentido estético e histórico-cultural. Tal escolha justifica-se, dentre outras possibilidades relevantes de pesquisa, por serem tais obras a base de um projeto levado a cabo pelo Programa Institucional de Bolsas de Iniciação à Docência (Pibid) da área de História da Pontifícia Universidade Católica do Rio Grande do Sul (PUCRS).

Nessa perspectiva, pode-se ressaltar que os projetos de Educação Patrimonial, as saídas a campo e as diferentes práticas de visitação orientada de estudantes e professores aos espaços públicos da memória social e da história, no âmbito do entendimento crítico e reconhecimento dos acervos e bens históricos, culturais e artísticos de uma sociedade, sem dúvida constituem importantes procedimentos pedagógicos no ensino de história. As possibilidades educativas e formativas dessas práticas, compreendidas pedagogicamente, tanto podem oferecer benefícios à aprendizagem significativa dos estudantes do ensino básico, quanto revelar aspectos cruciais na formação e qualificação dos professores de história (Zabala, 2010, p.37).

Em vista disso, o Pibid da área de História da PUCRS vem desenvolvendo junto às escolas públicas estaduais, notadamente, um projeto de educação histórica baseado na valorização da pesquisa, no estudo das fontes imagéticas e na visitação aos espaços públicos constitutivos da memória e da história regional e local. Dessa maneira, com o propósito fundamental de promover uma educação crítica e cidadã, renovando os métodos de ensino e qualificando o processo de formação de professores, esse projeto visa integrar universidade e escola num amplo programa de ações pedagógicas que envolvem, principalmente, estudantes do ensino básico das escolas públicas e licenciandos do curso de História da PUCRS. Nesse trabalho, além de elementos alusivos à educação patrimonial, problematiza-se a forma pela qual os murais elaborados pelo artista podem ser abordados nas ações educativas desenvolvidas com 
alunos do ensino fundamental e médio, especialmente no que se refere à imagem do gaúcho e ao estudo de temas regionais, entre outros.

\section{Problemas}

Há muitos anos, no campo das ações de ensino, a relação entre alunos e imagens tem sido quase sempre superficial. Veiculadas em livros didáticos apenas como forma de ilustrar textos, capítulos e conclusões textuais, esses objetos passam a ser coadjuvantes na construção do conhecimento histórico. Um exemplo muito claro dessa questão no ensino de História do Brasil é, pois, o trabalho de Victor Meirelles e Pedro Américo. A primeira missa no Brasil e Independência ou Morte (ou O grito do Ipiranga) foram obras que, durante muito tempo, apenas materializaram, em tintas e cores, o "descobrimento" e a Independência do Brasil, ou seja, foram utilizadas, apenas, como apêndice visual do texto que narrava ambos os fatos. Mesmo que tais produções pictóricas tenham se articulado, igualmente, no construto da nação, o fato é que, quando levadas à sala de aula, seus usos ficaram restritos, muitas vezes, à representação visual dos fatos. ${ }^{2}$

Por certo, tais pinturas foram elaboradas com o intuito de, mediante uma narrativa pictórica, trazer ao público a que se destinavam determinados acontecimentos da história do Brasil. No entanto, é precisamente essa questão, que aborda os entornos construtivos e constitutivos de uma imagem, que não são problematizados em sala de aula. Questionamentos sobre sua produção - se houve ou não um comitente, quais suas funções, em que momento ela foi elaborada e, principalmente, quem a elaborou - foram perguntas ignoradas em prol do seu uso ilustrativo e não pedagógico. Nesse caso, como comentado anteriormente, a imagem acaba por perder suas particularidades como fonte para, apenas, ser uma figura em um livro.

As novas abordagens metodológicas que têm a imagem como o objeto e, ainda, como fonte de ensino, vêm sendo trabalhadas por diversos intelectuais, dentre os quais o medievalista Jean-Claude Schmitt. Em seu livro O corpo das imagens. Ensaios sobre cultura visual na Idade Média, o autor realiza uma interessante reflexão acerca do uso das imagens por parte dos historiadores e visa alicerçar uma metodologia de análise que contemple as várias funções 
oferecidas, sem reduzir as imagens a mera ilustração do texto escrito nem, tampouco, reprodução fiel do contexto vivido pelo artista. Para o autor,

Certos [historiadores] procuram (ou ainda procuram) nas imagens a representação mais ou menos fiel, logo mais ou menos confiável aos olhos do historiador, das realidades ... Mas essa utilização imediata das imagens pelos historiadores nada nos diz das próprias imagens, nem de sua razão de ser e nem da natureza, diferentemente complexa, do processo de representação. Engana-se redondamente quem pensa que, para os homens do passado, como de resto para nós, poderia haver algo do real, independentemente da consciência dos atores sociais e da expressão que oferecem em suas obras. (Schmitt, 2007, p.26)

Além de Schmitt, o já citado Peter Burke, na obra Testemunha ocular: história e imagem, oferece igualmente uma crítica aos estudiosos que percebem a imagem apenas como parte ilustrativa de um texto sem, no entanto, lhes conferir a importância que lhes cabe. Por tal motivo, o historiador atenta às possibilidades que seu estudo oferece, uma vez que não devem ser tomadas apenas como ilustração de conclusões de textos já desenvolvidos. Para Burke (2004, p.12), o trabalho com imagens deve, pois, impulsionar e propor novos questionamentos e problemáticas na escrita e conhecimento da história. Assim,

Quando utilizam imagens, os historiadores tendem a tratá-las como meras ilustrações, reproduzindo-as nos livros sem comentários. Nos casos em que as imagens são discutidas no texto, essa evidência é frequentemente utilizada para ilustrar conclusões a que o autor já havia chegado por outros meios, em vez de oferecer novas respostas ou suscitar novas questões.

Outra questão de grande relevância nesse contexto é, pois, a percepção das funções exercidas pelas imagens. Não apenas sua significação simbólica constitui-se como elemento primordial para a análise e o trabalho com fontes imagéticas. É, sobretudo, a partir de suas funcionalidades e, muitas vezes, diálogos com o espaço onde está inserida, que muito de sua representatividade se apresenta ao pesquisador. Assim, uma imagem, qualquer que seja seu conteúdo, quando não observadas as suas funções, pressupõe uma análise arbitrária e incompleta. Como afirma Schmitt (2007, p.27), 
a sua função [imagem] é menos representar uma realidade exterior do que construir o real de um modo que lhe é próprio. Para o historiador, a questão será assim menos a de isolar e de ler o conteúdo da imagem, do que compreender sua totalidade, em sua forma e estrutura, em seu funcionamento e suas funções.

Nesse sentido, "analisar a arte em sua especificidade e em sua relação dinâmica com a sociedade que a produziu" (Schmitt, 2007, p.33) torna-se o eixo central da proposta de estudo acerca dos murais de Aldo Locatelli no Palácio Piratini. Da mesma maneira que se buscam subsídios em sua prática artística, igualmente os contornos contextuais, especialmente os relacionados aos elementos socioculturais e políticos do Rio Grande do Sul na década de 1950, oferecem sólidas bases para compreender a profusão de imagens criadas pelo artista no espaço governamental. Junto a isso, os contatos que o artista estabeleceu com a intelectualidade sul-rio-grandense também se revestem de singular relevância e complementam a ampla rede de significações geradas na produção das obras muralísticas.

É importante frisar, também, que na produção de uma obra de arte por encomenda, como foi o caso das realizadas por Locatelli para o palácio governamental, é necessário pensar sua elaboração a partir dos pressupostos daquele que a encomendou, associados aos do artista que irá realizar tal tarefa. Esse ponto, relacionado, também, às funções da imagem, encontra subsídios quando Schmitt afirma que "na relação entre a forma e a função da imagem, encontra-se expressa a intenção do artista, do financiador e de todo o grupo social envolvido na realização da obra" (Schmitt, 2007, p.46). Levando tal aspecto em consideração, serão percebidas as particularidades imagéticas de cada pintura elaborada pelo artista, que não só apontam para aspectos precisos do contexto político em que foram encomendadas, mas, também, evidenciam os seus próprios valores e princípios.

Se, por um lado, essas relações auxiliam na compreensão das composições elaboradas por Locatelli no Palácio Piratini, por outro, perceber a subjetividade do artista igualmente contribui para a construção de um conhecimento mais profundo acerca das imagens criadas e plasmadas nos murais que se pretende analisar. Mesmo que as obras tenham sido encomendadas e que Locatelli tenha estudado e interagido com outros intelectuais a respeito da temática que deveria realizar, as formas e a representação são criações que lhe são próprias. 
Nesse sentido, mesmo que a técnica e a prática artística cumpram papel basilar na elaboração das pinturas, não se pode desconsiderar o mundo interno do artista, o qual se manifesta em seus sentimentos, pensamentos e emoções. Quando de percebe que Aldo Locatelli pinta, em alguns dos murais do palácio do governo, os seus valores, a sua família e até mesmo autorretratos, visualizam-se e compreendem-se em maior profundidade as suas composições.

Mesmo que Locatelli, com base em sua subjetividade, tenha elaborado imagens alusivas aos aspectos mais peculiares da cultura sul-rio-grandense, é importante ressaltar que ele era italiano. Há que se considerar, portanto, que por mais integrado que ele estivesse ao povo e aos costumes do Rio Grande do Sul, mesmo com o passar dos anos sua origem ainda poderia influenciar totalmente o processo de criação. O que se quer ressaltar com esse argumento é o fato de estar presente o olhar estrangeiro, especialmente na criação dos murais alusivos ao aspecto histórico e formativo do estado.

Contudo, por ter permanecido muito tempo em terras gaúchas e ter-se apropriado das particularidades e cultura desse estado, pode-se dizer que Locatelli não se configura como um viajante. No entanto, é interessante citar a referência que Belluzzo faz a respeito dos artistas que elaboram representações acerca de uma realidade que lhes é diferente. Segundo a autora, "o olhar dos viajantes espelha, também, a condição de nos vermos pelos olhos deles" (Belluzzo, 1996, p.10). Ao serem observadas algumas imagens elaboradas por Locatelli, em especial a figura do gaúcho, é justamente essa relação que se estabelece: os observadores da obra se reconhecem na visão que Locatelli tem deles próprios.

Todas essas questões metodológicas, por certo, tiveram sua base nos postulados estabelecidos por Aby Warburg em fins do século XIX. Intelectual que se dedicou ao estudo e análise da imagem, ele as compreendeu a partir de suas especificidades e, ainda, de seu viés antropológico. Para Warburg, diversos elementos dialogam no estudo e análise de uma imagem: a relação do artista com seu meio e com os círculos intelectuais do período, o papel do comitente e a flexibilização da política de fronteira disciplinar. A metodologia de Warburg superou o isolamento que ameaçava a obra de arte e investigou "a complementação recíproca de documentos pictóricos e literários, a relação entre artistas e comitente, o entrelaçamento entre a obra de arte e o ambiente social e sua finalidade prática como objeto individual” (Bing, 2013, p.41). Essas questões 
se interligavam na tessitura da complexa rede de relações que a imagem estabelecia não apenas com seu meio, mas com todo seu entorno de produção. Como se estivesse no centro de uma teia, a imagem tece sua própria rede de significações.

Trazer os problemas de método e, igualmente, de análise imagética é fundamental para as novas propostas de estudo e uso de tais fontes em sala de aula. Se, por um lado, o aluno é instigado a perceber - e a construir - todo o entorno de produção da imagem, por outro, ele termina por elaborar novas percepções acerca de realidades que, desde sempre, eram verdades incontestes. Esse é o caso, por exemplo, da imagem do gaúcho na produção artística do Rio Grande do Sul. Elemento de fácil identificação - e significação - quando colocado em um palácio governamental e, ainda, elaborado por um artista italiano, diversas possibilidades de análise se abrem tanto para o professor quanto para o aluno.

\section{INQUIETAÇÕES}

Adentrar as grandes salas do segundo piso do Palácio Piratini é, pois, encontrar-se com as tintas, cores e traços de Aldo Locatelli. Artista italiano, chegou ao Rio Grande do Sul no ano de 1948, junto de Emílio Sessa e Adolfo Gardoni, para executar os painéis religiosos da Catedral São Francisco de Paula na cidade de Pelotas. Dada a grande repercussão de seus trabalhos, em 1951 recebeu a encomenda do então governador do Rio Grande do Sul, Ernesto Dornelles, para executar três murais de temática histórica no prédio do governo. Um ano depois, e com as obras já em andamento, Locatelli assinou novo contrato onde se comprometia a elaborar, no mesmo local, 18 painéis alusivos à lenda do Negrinho do Pastoreio, uma das mais significativas do folclore sulino.

Com o trabalho de Locatelli, o acervo passou a contar com importantes pinturas murais. Dentre elas, destacam-se a que está localizada na antessala do gabinete do governador, intitulada $O$ Estado que, segundo Fernando Corona (1973, p.14), "simbolizava a família unida pelo trabalho ante a riqueza agropastoril e a indústria”. Já no antigo salão de festas foram realizados os 18 murais alusivos à lenda do Negrinho do Pastoreio. Dada a sua importância, desde a realização dessas pinturas o espaço passou a chamar-se Salão Negrinho do Pastoreio. 
Por fim, na última grande sala do segundo andar, chamada Salão Alberto Pasqualini, encontram-se os dois trabalhos do artista centrados na temática histórica e formativa do Rio Grande do Sul: A fundação de Rio Grande e o imponente Formação histórico-etnográfica do povo rio-grandense. Sobre esse último, não só os seus $25 \mathrm{~m}^{2}$ transmitem a sensação de grandiosidade aos observadores. A maneira pela qual o artista trabalhou suas personagens e as distribuiu no plano imagético certamente contribui nesse sentido.

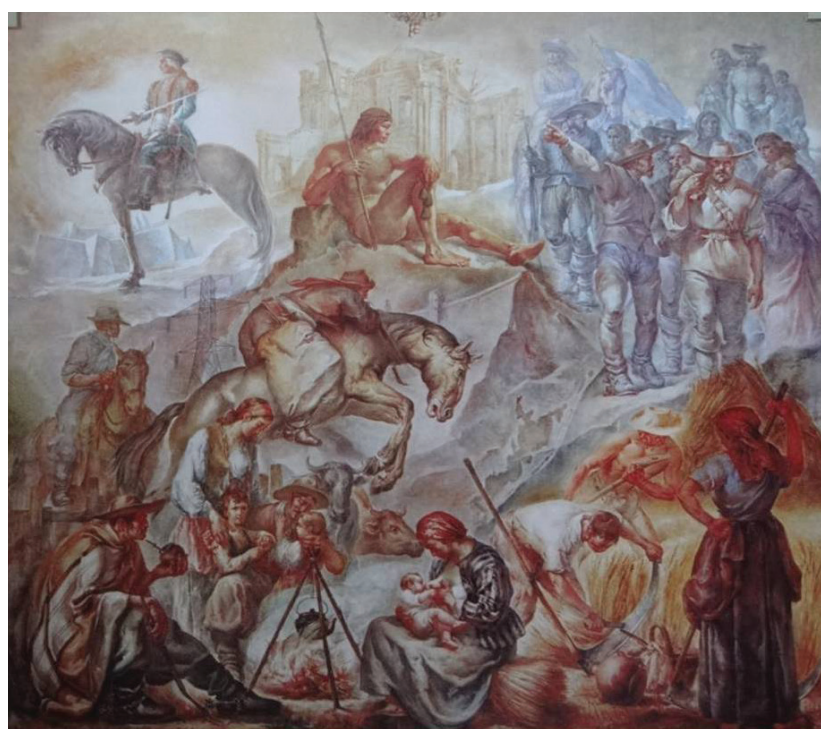

Figura 2 - Aldo Locatelli. A formação histórico-etnográfica do povo rio-grandense, mural em técnica mista, $25 \mathrm{~m}^{2}, 1951-1955$ Palácio Piratini, Porto Alegre, RS

Foi precisamente diante dessa obra, durante uma aula com alunos de ensino fundamental, que a questão da imagem do gaúcho tornou-se uma inquietação - e um ponto de partida - para a turma e para a organização de um projeto. Questionados sobre a personagem que teria maior destaque na pintura, a grande maioria apontou para o gaúcho que se encontrava no canto inferior esquerdo da obra. De posse de tal resposta, perguntou-se a eles, ainda, se teriam ideia do porquê do destaque de tal figura, ao que um aluno respondeu: "porque ele nos representa". Essa simples afirmação, que originou diversos outros questionamentos por parte dos colegas, colocou no centro do debate 
a importância do trabalho com fontes imagéticas. Não só isso, tal proximidade oportunizou a eles o contato com um material que, desde as primeiras aulas de história na escola, tinha por função, apenas, ilustrar o livro didático.

Nesse aspecto, tendo essas questões em vista, o trabalho com fontes imagéticas em sala de aula tornou-se a base dos questionamentos acerca do gaúcho e suas representações na pintura sul-rio-grandense. Por certo, todos os elementos que pautam a análise de imagens, conforme exposto anteriormente, foram utilizadas - de maneira mais simplificada - no trabalho com os alunos. No entanto, apenas para demarcar um ponto de partida, optou-se por lançar um desafio: que outras imagens dessa figura estavam presentes na produção artística do estado? Elas teriam alguma relação com a elaborada por Locatelli?

Assim, mapeando obras de Pedro Weingärtner, José Lutzenberger, Guido Mondin, Danúbio Gonçalves, Paulo Porcella e Nelson Jungbluth, por exemplo, estabeleceu-se uma rede onde tanto os elementos que apresentavam semelhanças quanto os que exibiam demarcadas diferenças foram relacionados entre si estabelecendo, assim, um interessante debate anacrônico. Foi partindo dessas questões, então, que o mural e, mais precisamente, o gaúcho presente na pintura de Locatelli foi, novamente, interrogado pelos alunos.

Como comentado anteriormente, a figura do gaúcho está localizada no canto inferior esquerdo da pintura. Com relação às demais, ele parece ser o enunciador da narrativa de Locatelli. E tal disposição e função, comparada às demais pinturas observadas, foi percebida pelos alunos pelo fato de o homem do pampa não estar executando nenhuma das atividades que o relacionam às lidas do campo - o que aparece em quase todas as outras imagens apresentadas. Para os alunos, esse homem era, portanto, o representante do Rio Grande do Sul.

A partir disso, diversos elementos puderam ser estudados e analisados em um trabalho colaborativo e interdisciplinar. A base das pesquisas empreendidas pelos alunos, por certo, esteve atrelada às particularidades das imagens e, igualmente, aos diversos elementos que estavam em seu entorno de produção. No caso específico do gaúcho, a compreensão de sua representatividade nos anos 1950 e a relação entre artista e comitente foram dois elementos basilares para o empreendimento da análise da imagem. ${ }^{3}$

O gaúcho que Locatelli faz enunciar sua obra foi elaborado sorvendo seu chimarrão, em frente a um fogo de chão que esquenta a água da chaleira 
suspensa no tripé. Além disso, sua vestimenta, constituída por botas, poncho, bombachas, chapéu e lenço no pescoço, marca sobremaneira as elaborações feitas a respeito do homem sul-rio-grandense. Considerando, assim, a importância dessa figura no quadro cultural regional, deve-se colocar que ela foi historicamente construída, chegando ao patamar de ser, até a atualidade, representante maior de um povo e cultura específicos. De acordo com Gutfreind (2007, p.241), "quando essa composição social colonial sul-rio-grandense [brancos, negros e mestiços] é representada no imaginário coletivo da sociedade atual, a multiplicidade de grupos sociais desaparece e sobressai-se um único tipo: o gaúcho".

Essa imagem, construída ao longo da história e colocada como símbolo identitário do Rio Grande do Sul a partir do movimento tradicionalista em fins da década de 1940, igualmente integra essa obra de Locatelli no sentido de culto às tradições e preservação dos valores que, inerentes a ele, imprimiu-os em toda uma sociedade. Assim, o que ratifica essa imagem no inconsciente coletivo rio-grandense é, justamente, o culto à vida campeira. Na medida em que esse movimento tinha como fundamento principal a preservação das tradições oriundas do interior e das paisagens da região da campanha, ela contrapunha-se a todos os aspectos urbanos que ameaçavam o passado e a tradição. De acordo com Ruben Oliven (2006, p.97), "O modelo que é construído quando se fala em tradições gaúchas - qualquer que seja a perspectiva de quem as cultua - está sempre calcado no campo, mais especificamente na região da Campanha ... e na figura do gaúcho, homem livre e errante que vagueia soberano sobre seu cavalo".

Interessante perceber, ainda, mesmo que a partir da profusão de imagens colocadas na narrativa circular do mural, que ela inicia com o gaúcho e, igualmente, é finalizada por ele. Nesse sentido, se tomarmos o gaúcho como o enunciador da narrativa, como já apontado, perceberemos que, no primeiro plano e na direção que segue seu olhar, uma série de outras imagens e personagens são apresentadas ao observador. Não apenas a família, que está junto dele, mas, sobretudo, a pecuária e a agricultura - que estão representadas, respectivamente, pelas cabeças de gado e pelos açorianos que cortam o trigo logo à sua frente - são mostradas como base fundamental na qual o estado estava assentado economicamente. Na sequência, e com interessante mudança de tonalidades e acurado trabalho com a perspectiva, estão os aspectos 
históricos e étnicos do Rio Grande do Sul. Assim, bandeirantes, portugueses e o índio missioneiro apresentavam a configuração formativa do estado.

Interessante perceber, afora essas questões formais, a maneira pela qual Locatelli serviu-se de técnicas pictóricas e plásticas para construir o mural e significá-lo a partir da ideia de passado e presente. Essa questão também oferece subsídios para se compreender a forma como ele organizou tal narrativa. No primeiro plano da obra, onde as figuras têm mais destaque em função da perspectiva, as cores mostram-se mais escuras e definidas se comparadas às subsequentes. Nesse sentido, para articular as imagens e as impregnar de um tom monumental e grandioso, o artista valeu-se da perspectiva aérea. Esta, que "define as mudanças de cor e tons dependendo da posição do objeto" (Paixão, 1977, p.45), permite, afora o destaque dado a determinadas figuras, sua hierarquização em função de sua relevância no processo histórico rio-grandense. Assim, além da disposição circular, a perspectiva, aliada ao uso das cores e do desenho geométrico, permite a visualização do constante diálogo entre os elementos formativos da sociedade sulina.

A maneira pela qual esses elementos compositivos estão dispostos na obra auxilia na percepção da relação entre tempo e espaço. Enquanto as imagens alusivas ao resultado da formação étnica - o gaúcho - e às primeiras atividades econômicas do Rio Grande do Sul - agricultura e pecuária - estão destacadas no primeiro e segundo planos, conforme a narrativa aproxima-se do passado, suas representações vão adquirindo tonalidades mais claras. Nesse sentido, não apenas a perspectivação do espaço conduz o olhar do observador de forma ascendente, mas também as imagens referentes a tempos históricos diferentes igualmente são demarcadas e possibilitam o seu entendimento.

Assim, se por um lado, e servindo-se de tais técnicas plásticas, Locatelli inicia a narrativa com o gaúcho, por outro, ele a encerra com o mesmo tipo campeiro. Este, que está ao centro do mural, saltando sobre o mapa do Rio Grande do Sul, parece conter a síntese do que foi apresentado pelo artista. Apesar de ter trabalhado com o ritmo estático nesse mural, Locatelli o leva a adquirir movimento na medida em que empregou na cena e na figura a expressividade necessária (Paixão, 1977, p.44).

Podendo apenas ser a síntese de toda uma construção que se pautou nos temas históricos e formativos do Rio Grande do Sul, tal elemento de destaque no mural entrava, igualmente, em acordo com a encomenda de Ernesto 
Dornelles que, além de plasmar seus ideais como governante, materializou elementos que também lhe eram pessoais. Ao comentar essa obra, Dornelles afirmava que ela sintetizava "a flama que no evolver da história e, em todos os tempos, iluminou a alma popular na ânsia de acesso a um mundo mais feliz e, verdadeiramente, cristão" (Zukauskas, 1955, p.24).

A respeito disso, e relacionando a produção do artista com os desígnios de seu comitente, um elemento inserido nesse mural ganha destaque. Conforme visto, eram muitas as imagens que Locatelli teria de inserir em $A$ formação histórico-etnográfica do povo rio-grandense. Afora ter de articular elementos do passado com a exaltação que se fazia deste na construção identitária, Ernesto Dornelles, aquele que vislumbrou a obra, solicitou ainda que o artista colocasse no mural elementos que referendassem os seus feitos como governador do estado. Tal consideração deve-se a um comentário que o então governador faz quando entrevistado por repórteres da Revista do Globo. Surpreendido Dornelles na Sala de Reuniões do palácio governamental, onde observava acuradamente o mural, o jornalista assim descreve a cena: “A decoração é do pintor Aldo Locatelli, mas gente bem informada nos segredou que a inspiração para alguns dos motivos é do general [Ernesto Dornelles]...” (Zukauskas, 1955, p.28).

Assim, tem explicação a representação, não muito destacada na obra, da torre de energia elétrica e da barragem da usina hidrelétrica. Ao sinalizar os passos à modernidade do estado sulino, tais imagens correspondiam, igualmente, a todo um discurso ideológico que colocava em evidência a plataforma política do desenvolvimentismo. Este, fundamentado no "desenvolvimento independente do Brasil através da industrialização" (Rodrigues, 1999, p.20), promovia a modernização dos setores mais importantes da economia. Era de suma importância para esse desenvolvimento, também, um amparo tecnológico que sustentasse a industrialização. Entre esses pontos, sem dúvida, estavam os planos de eletrificação que se estenderam pelo estado a partir do final da década de 1940 e que, "além de facilitar e baratear um importante insumo industrial, [pretendiam] conter o êxodo rural” (Müller, 1979, p.372). Assim, a eletrificação do Estado, que tomou grandes proporções no governo de Ernesto Dornelles, visava acelerar a economia rio-grandense, mesmo que tamanho projeto não coubesse nas contas do estado. 
Ao lado de tais elementos específicos, que conjugam a produção do artista e os intentos do governo, Locatelli finaliza sua narrativa com a figura do gaúcho como a grande síntese da cultura e da sociedade sulinas. Encarnando não apenas valores memorativos que aludiam ao passado, tal imagem encerra, igualmente, os mais altos e nobres valores morais legados por seus antepassados. Assim, tal qual a confluência cultural encontra no gaúcho a sua mais rica expressão, Locatelli serve-se dele para finalizar sua narrativa pictórica.

Perceber, na voz dos alunos, a maneira pela qual o mural $A$ formação histórico-etnográfica do povo rio-grandense foi elaborado por Aldo Locatelli é, pois, fazer confluir uma gama de elementos que, anacronicamente, dialogam entre si. É fazer, igualmente, fontes diversas debaterem e trazerem outras respostas a questões já postas. Assim, quando a imagem torna-se o centro do debate - e não a sua margem - novas questões e problematizações tornam-se possíveis. Novos entendimentos acerca do gaúcho bem como da construção de sua imagem são oportunizados. No caso do gaúcho de Locatelli, em especial, mais que nos representar, para falar como o aluno citado no início deste artigo, ele é o elemento que nos apresenta historicamente.

Trabalhar a imagem a partir de suas especificidades e particularidades é, também, questioná-la como fonte. É tirá-la do lugar comum da ilustração dos fatos e dar-lhe protagonismo como fonte e objeto de estudo. Nesse sentido, as inúmeras possibilidades oferecidas pelas imagens permitem a construção de novos conhecimentos, especialmente quando problematizadas em sala de aula. Assim, o projeto que se articulou entre alunos do Pibid/História da PUCRS e os murais de Aldo Locatelli no interior do palácio do governo tem por base, justamente, a ideia de que as imagens, quando trabalhadas a partir do amplo leque de referências que portam, oportunizam novas e diferentes percepções não só do processo histórico, mas, igualmente, das produções artísticas.

\section{REFERÊNCIAS}

ASSIS BRASIL, Luis Antônio de. Palácio Piratini. Porto Alegre: Nova Prata, 2007.

BELLUZZO, Ana Maria. O Brasil dos viajantes. Revista USP, São Paulo, n.30, p.8-19, jun./ago. 1996.

BING, Gertrud. Prefácio à edição de 1932. In: WARBURG, Aby. A renovação da Antiguidade pagã: contribuições científico-culturais para a história do Renascimento europeu. Rio de Janeiro: Contraponto, 2013. p.41. 


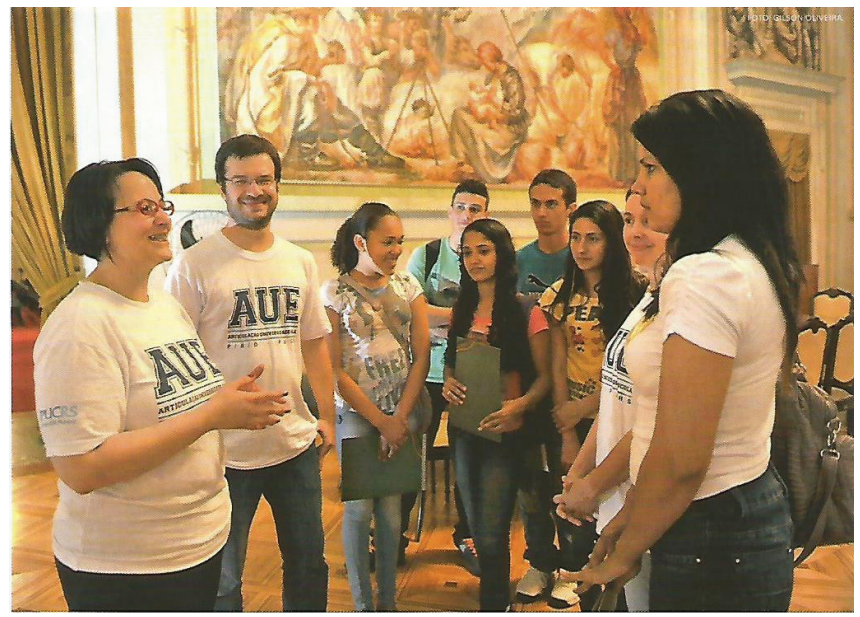

Figura 3 - Estudantes do Ensino Básico e

Licenciandos do Pibid/PUCRS, Palácio Piratini

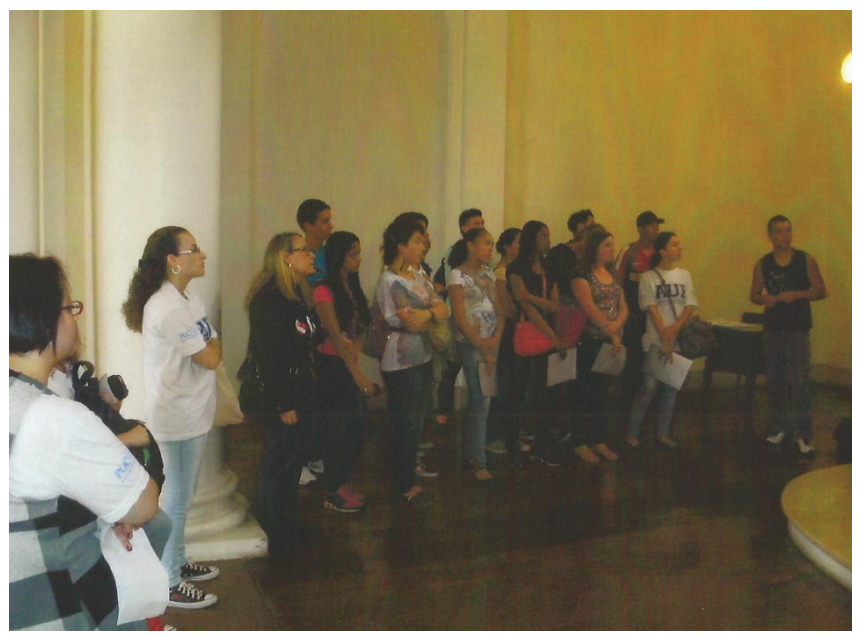

Figura 4 - Estudantes da Escola Básica e grupo do Pibid/PUCRS, Palácio Piratini 
BITTENCOURT, Circe. Livros didáticos entre textos e imagens. In: (Org.) $\mathrm{O}$ saber histórico na sala de aula. São Paulo: Contexto, 2009.

BURKE, Peter. Testemunha ocular: história e imagem. Bauru, SP: Edusc, 2004.

COLI, Jorge. Como estudar a arte brasileira do século XIX. São Paulo: Ed. Senac, 2005.

CORONA, Fernando. Palácios do Governo do Rio Grande do Sul. Porto Alegre: Corag, 1973.

FERMIANO, Maria Belintane; SANTOS, Adriana S. Ensino de História para o fundamental: teoria e prática. São Paulo: Contexto, 2014.

FERREIRA FILHO, Arthur. Palácio Piratini. Porto Alegre: IEL, 1985.

GUTFREIND, Ieda. O gaúcho e sua cultura. In: CAMARGO, Fernando; GUTFREIND, Ieda; REICHEL, Heloisa Jochims. História geral do Rio Grande do Sul. v.1. Passo Fundo: Méritos, 2007.

MÜLLER, Geraldo. A economia política gaúcha dos anos 30 aos 60. In: DACANAL, José Hildebrando; GONZAGA, Sérgius (Org.) RS: economia e política. Porto Alegre: Mercado Aberto, 1979.

OLIVEIRA, Luciana da Costa de. O Rio Grande do Sul de Aldo Locatelli: arte, historiografia e memória nos murais do Palácio Piratini. Dissertação (Mestrado em História) - Faculdade de Filosofia e Ciências Humanas, Pontifícia Universidade Católica do Rio Grande do Sul (PUCRS). Porto Alegre, 2011.

OLIVEN, Ruben. A parte e o todo: a diversidade cultural no Brasil-nação. Petrópolis: Vozes, 2006.

PAIXÃO, Antonina Zulema D’Ávila. Análise estética da pintura de Aldo Locatelli: técnica e arte, do embasamento clássico ao expressionismo figurativo. Dissertação (Livre Docência) - Instituto de Letras e Artes, Fundação Universidade de Pelotas. Pelotas, 1977.

RODRIGUES, Marly. A década de 50: populismo e metas desenvolvimentistas no Brasil. São Paulo: Ática, 1999.

SCHMITT, Jean-Claude. O corpo das imagens: ensaios sobre cultura visual na Idade Média. Bauru, SP: Edusc, 2007.

ZABALA, Antoni. A prática educativa: como ensinar. Porto Alegre: Artmed, 2010.

ZUKAUSKAS, Joseph. Dornelles: “Se chamado, voltarei”. Revista do Globo, Porto Alegre, n.635, 2 abr. 1955.

\section{NOTAS}

${ }^{1}$ O Palácio Piratini, sede do Poder Executivo do Rio Grande do Sul, é um prédio eclético com predominância neoclássica, projetado pelo arquiteto francês Maurice Gras (18731954) no ano de 1909 e tombado pelo Patrimônio Histórico Nacional em 2002. Afora sua 
importância política, o prédio sempre estabeleceu diálogo muito próximo com as artes, não só por sua arquitetura e conjunto escultórico, o qual foi elaborado por Paul Landowski (1875-1961) e Vasco Prado (1914-1998), mas sobretudo pelas diversas pinturas que integraram seu patrimônio, especialmente as elaboradas por Antônio e Dakir Parreiras, Décio Villares, Lucílio de Albuquerque e Augusto Luis de Freitas. Constituem obras de gênero histórico dos anos 1910 a 1930 e permaneceram no palácio até o momento da contratação de Aldo Locatelli, na década de 1950, quando executou os murais de temática histórica e folclórica. As pinturas anteriores foram encaminhadas a museus e demais espaços de memória do estado. Para mais detalhes, ver: CORONA, 1973; ASSIS BRASIL, 2007; FERREIRA FILHO, 1985.

${ }^{2}$ As referências às obras de Pedro Américo e Victor Meirelles, neste estudo, estão centradas, pois, na forma com a qual foram utilizadas como ilustração dos fatos propriamente ditos. Não se objetiva, então, analisá-las a partir de suas inúmeras implicações históricas e artísticas, uma vez que, para isso, seriam necessárias outras abordagens e diferentes incursões metodológicas. Para mais detalhas, ver: COLI, 2005.

${ }^{3}$ Importa mencionar que se realizou em sua totalidade a análise do mural A formação histórico-etnográfica do povo rio-grandense. No entanto, tendo em vista a complexidade do mural, optou-se por apresentar, neste trabalho, apenas as diretrizes que nortearam a análise da imagem do gaúcho. As análises dos murais elaborados por Aldo Locatelli no Palácio Piratini podem ser encontradas em: OLIVEIRA, 2011.

Artigo recebido em 5 de maio de 2017. Aprovado em 7 de agosto de 2017. 